\title{
Resin Based Materials used to Observing the Variations of the Origin of the Superior Thyroid Artery with Importance in Cervical and Cranial Pathology
}

\author{
PETRU BORDEI ${ }^{1}$, DAN MARCEL ILIESCU ${ }^{1}$, LAVINIA MARIA RUSALI ${ }^{1}$, RAZVAN HAINAROSIE ${ }^{2}$, RADU CRISTIAN JECAN ${ }^{2,3,4}$, \\ CRISTIAN CONSTANTIN POPA ${ }^{2,5 *}$, VALERIU ARDELEANU ${ }^{1,4,6,7}$ \\ 'Ovidius University, Faculty of Medicine, 1 Universitatii Alley, 900470, Constanta, Romania \\ ${ }^{2}$ Carol Davila University of Medicine and Pharmacy, 37 Dionisie Lupu Str., 020021, Bucharest, Romania \\ ${ }^{3}$ Emergency Clinical Hospital Agrippa Ionescu, 7 Ion Mincu, 011356, Bucharest, Romania \\ ${ }^{4}$ Arestetic Clinic, 78 Brailei, 800098, Galati, Romania \\ EUniversity Emergency Hospital, 2 ${ }^{\text {nd }}$ Surgical Department, 169 Splaiul Independentei, 050098, Bucharest, Romania \\ ${ }^{6}$ Dunarea de J os University, Faculty of Medicine and Pharmacy, 47 Domneasca Str., 800008, Galati, Romania \\ 'General Hospital CF, 5-7 Alexandru Moruzzi Str., 800223, Galati, Romania
}

The superior thyroid artery shows a great variability in what concerns its origin. Most often, it appears as an independent branch of the external carotid artery, as its first collateral branch, or directly from the common carotid or at its terminal level. The superior thyroid artery origin was evaluated on 144 cases, using as study methods the dissection (39 cases), the plastic injection (22 cases) and the CT angiography evaluation (83 cases). It was studied, by percentage, the originating artery of the superior thyroid artery, the relation to the bifurcation of the common carotid artery, the neighboring arterial branches and the surface of the external carotid on which originated, the caliber of the external carotid artery before and after the origin of the superior thyroid artery. Most commonly, in 89 cases (61.80\%), we describe the origin of the superior thyroid artery from the external carotid artery; from the common carotid artery originated 31 superior thyroid arteries (21.53\%); at the level of the bifurcation of the common carotid artery, the superior thyroid artery had its origin in 21 cases (14.58\%); in 2 cases (1.39\%) we encountered the superior thyroid artery originating from a thyrolingual trunk and in one case (0.69\%), we met a thyro-linguo-facial trunk. The superior thyroid arteries may originate as an independent artery or as arterial trunks in varying proportions. When the origin of the superior thyroid artery is from the terminal common carotid, we propose to use the expression of terminal branching or the common carotid artery trifurcation. The results of our study are similar to those found in international literature, with statistical differences that may be attributed primarily to the total number of cases on which we worked and also working methods or may be attributed to other causes, such as the geographic area where the study was conducted and the amount of time the results were obtained.

Keywords: superior thyroid artery, variations, common carotid artery trifurcation, terminal branching

The superior thyroid artery shows a great variability in what concerns its origin, as evidenced also in literature. Most often, it appears as an independent branch of the external carotid artery, as its first collateral branch [1-5], directly from the common carotid or at its terminal level, and rarely it may arise from the external carotid artery bya common trunk with other collaterals: thyro-lingual trunk or thyro-lingo-facial trunk. According to Testut $[6,7]$, the superior thyroid artery arises from the external carotid artery immediately above its origin and sometimes directly from the terminal level of the common carotid artery. Also $[6,7]$ quotes, as possible versions and variations of the origin of the superior thyroid artery, the origin from the common carotid artery, common trunk with the lingual artery (not quite rare), or even the absence of one of the two superior thyroid arteries, a situation when is substituted by an arterial branch that originate from the inferior thyroid artery of the same side or being compensated by the superior thyroid artery of the opposite side. Same author $[6,7]$ mention the arterial duplicity, one of the branches (almost always the superior laryngeal artery) taking birth as an isolated branch from the external carotid artery or even from the lingual or facial artery; also, one of the most frequent variation is the passage of the superior thyroid artery through the thyroid cartilage. According to [8], the origin of superior thyroid artery may be at the level of the carotid bulb, when the common carotid artery seems to trifurcate. Sometimes, the artery may be partially replaced in its supplied territory by a superior laryngeal artery originating from the external carotid artery or an accessory superior thyroid artery that originates from the lingual artery [8]. As [9] states, the superior thyroid artery emerges above the bifurcation of the common carotid artery, from the anterior surface of the external carotid artery; rarely, it may appear as the second collateral branch of the external carotid artery, while the first branch being the ascending pharyngeal artery.

Also [10] describe the origin superior thyroid artery from the external carotid artery in 50\% of cases, in $20 \%$ cases from the bifurcation of the common carotid, in $11 \%$ cases from the common carotid artery, in $2 \%$ of cases describe the presence of a thyro-lingual trunk originating from the external carotid artery, in less than $1 \%$ of cases describes a thyro-lingual trunk originating from the common carotid and also in less than $1 \%$ of cases a thyro-linguo-facial trunk originating from the external carotid artery. Another author [11] cites the existence of a thyro-lingual trunk originating from the external carotid artery in $4 \%$ of cases and a thyrolinguo-facial trunk in $0.6 \%$ of cases. For [12,13], the origin of superior thyroid artery is located near the origin of the external carotid, [14] describes a case of common carotid high-ending level, that splits into the superior thyroid, the 
lingual, the facial and the occipital arteries. Also [15], on a 25 cases angiographic study shows, in descending order of the percentages, more than $70 \%$ of the origins from the external carotid artery $(71.5 \%$ on the right and $72.5 \%$ on the left), followed by the bifurcation of the common carotid artery ( $21 \%$ on the right and $18.5 \%$ on the left) and also unusual origins such as the common carotid or internal carotid arteries, with $4 \%$ each.

\section{Experimental part}

\section{Materials and methods}

The superior thyroid artery origin was evaluated on 144 cases, using as study methods the dissection, the plastic injection and the CT angiography evaluation. The dissection (39 cases) was performed on formalin preserved adult human cadavers and also on fresh or formalin preserved fetuses, ages 5 to 8 months. Also on fresh fetal cadavers (22 cases) we performed the plastic injection of the common carotid arteries, followed by dissection or corrosion. We used the Technovit 7143, a German selfcuring resin based on methyl methacrylate in the form of powder and liquid while the corrosion was made with sodium hydroxide. The angioCT evaluation (83 cases) was performed on two CT Scanners, GE LightSpeed 16Slice CT and GE LightSpeed CT Slice VCT64. It was studied, by percentage, the originating artery of the superior thyroid artery, the relation to the bifurcation of the common carotid artery, the neighboring arterial branches and the surface of the external carotid on which originated, the caliber of the external carotid artery before and after the origin of the superior thyroid artery.

\section{Results and discussions}

Of the 144 cases, 76 cases were right superior thyroid arteries ( $52.78 \%$ of cases) while 68 cases were left superior thyroid arteries (47.22\% of cases).

Most commonly, in 89 cases ( $61.80 \%$ of cases), we describe the origin of the superior thyroid artery from the external carotid artery, 47 cases being on the right ( $61.84 \%$ of all the right thyroid arteries) and 42 cases on the left (61.76\% of all the left thyroid arteries). The level of the origin from the external carotid artery was located at 1.1 to $22 \mathrm{~mm}$ from the origin of this artery, on the right side the distances being 1.1 to $14 \mathrm{~mm}$ and 2 to $22 \mathrm{~mm}$ on the left. In 64 cases (71.91\% of the 89 cases) the arteries started from the medial aspect of the external carotid artery (fig. 1), 36 cases on the right side ( $76.6 \%$ of the 47 cases) and 27 cases on the left (64.29\% of the 42 cases). On the postero-medial aspect of the external carotid artery (Fig.

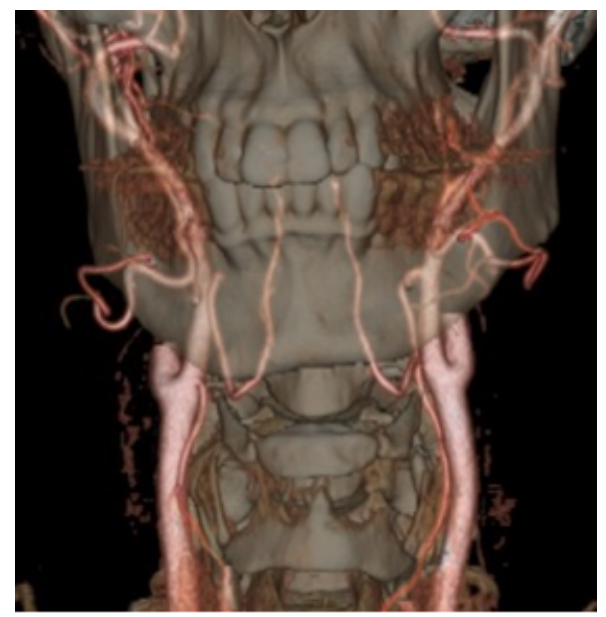

Fig. 1 The superior thyroid arteries originate on the medial aspect of the external carotid artery, the left one showing a higher origin

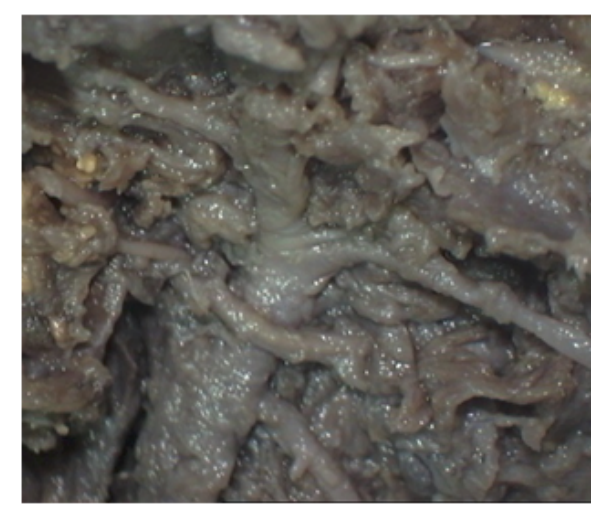

Fig. 2 The right superior thyroid artery originated from the posterior medial surface of the common carotid artery. Between the superior thyroid and the lingual arteries there is a distance of $2 \mathrm{~cm}$.

2), 22 superior thyroid arteries had their origins ( $24.72 \%$ of 89 cases), 8 cases being on the right ( $17.02 \%$ of 47 cases) and 14 cases on the left (35 71\% of 42 cases). In only 3 cases (3.37\% of those 89 cases) the thyroid arteries had their origins on the antero-medial aspect of the external carotid artery, all cases being on the right side $(6.38 \%$ of 47 cases).

From the common carotid arteryoriginated 31 superior thyroid arteries ( 21.53 out of 144 cases), 17 cases being on the right (22.37\% of the right thyroid arteries) and 14 cases on the left ( $20.59 \%$ of the left thyroid arteries). The level of the origin from the common carotid artery was at 1.5 to $5 \mathrm{~mm}$ of its terminal ramification, on the right side the distances being 2 to $5 \mathrm{~mm}$ and 1.5 to $4 \mathrm{~mm}$ on the left. In 15 cases (48.39\% of the 31 cases) the arteries had their origins on the medial aspect of the common carotid artery, 8 cases being on the right (47.06\% of the 17 cases) and 7 cases on the left (50\% of 14 cases). From the posteromedial aspect of the common carotid artery the superior thyroid artery started in 8 cases $(25.80 \%$ of 31 cases), 6 cases on the right ( $32.59 \%$ of 17 cases) and 2 cases on the left ( $14.29 \%$ of 14 cases). Five superior thyroid arteries (16.13\% of cases) originated from the antero-medial surface of the common carotid arteries, 2 cases on the right $(11.76 \%$ of 17 cases) and 3 cases on the left $(21.43 \%$ of 14 cases). In 3 cases (9.68\% of 31 cases), the superior thyroid arteries had their origins on the posterior aspect of the common carotid artery, one case being on the right ( $5.88 \%$ of 17 cases) and 2 cases on the left ( $14.29 \%$ of 14 cases).

At the level of the bifurcation of the common carotid artery, the superior thyroid artery had its origin in 21 cases ( $14.58 \%$ of all cases), 11 cases on the right $(14.47 \%$ of the right superior thyroid arteries) and 10 cases on the left (14.71\% of the leftsuperior thyroid arteries). Of the 21 cases, in 14 cases (66.67\% of 21 cases), the superior thyroid arteries had their origins on the medial aspect of the carotid bifurcation, 9 cases being on the right ( $81.81 \%$ of 11 cases) and 5 cases on the left (fig. 3) (50\% of 10 cases). In 5 cases the superior thyroid artery origin was localized on to the postero-medial face ( $23.81 \%$ of 21 cases), 1 case being on the right ( $9.09 \%$ of 11 cases) and 4 cases on the left ( $40 \%$ of 10 cases). In only 2 cases $(9.52 \%$ of 21 cases), the superior thyroid arteries origin was located on the anteromedial aspect of the bifurcation (fig. 4), 1 case being on the right ( $9.09 \%$ of 11 cases) and the other on the left ( $10 \%$ of 10 cases).

In 2 cases ( $1.39 \%$ of the 144 cases) we encountered the superior thyroid artery originating from a thyro-lingual trunk, both cases on the left ( fig. 5). In one case the arterial trunk, with a length of $2.8 \mathrm{~mm}$, originated from the medial 


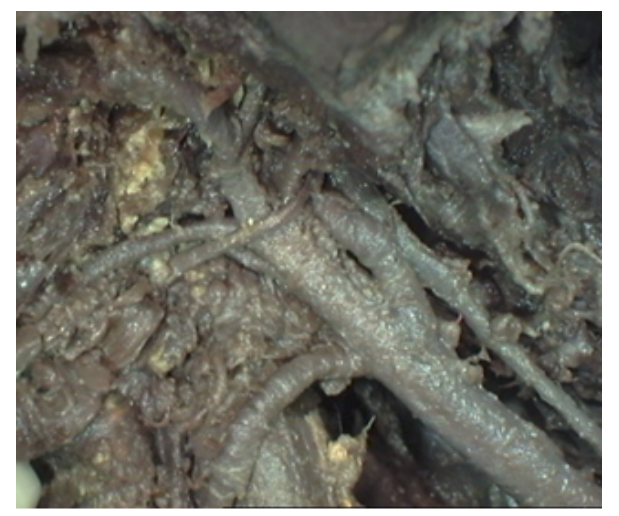

Fig. 3 The left superior thyroid artery originates from the medial aspect of the common carotid terminal branching (trifurcation).

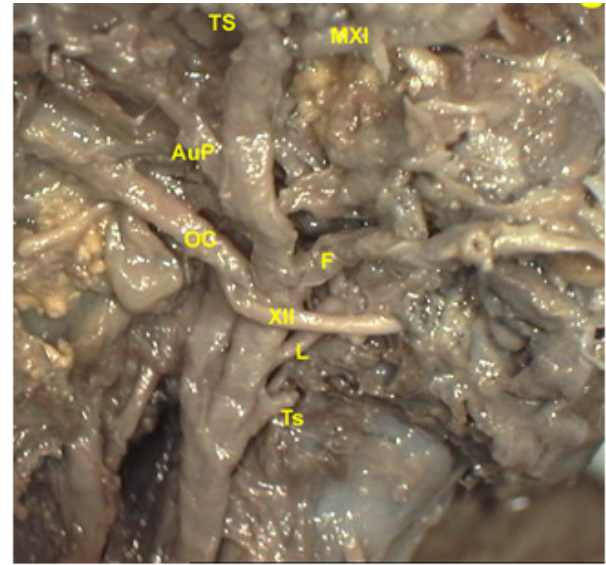

Fig. 4 The superior thyroid artery originating from the terminal branching of the common carotid artery, slightly anterior and medial to the external carotid artery, on the same plane with the internal carotid artery (Ts-superior thyroid artery)

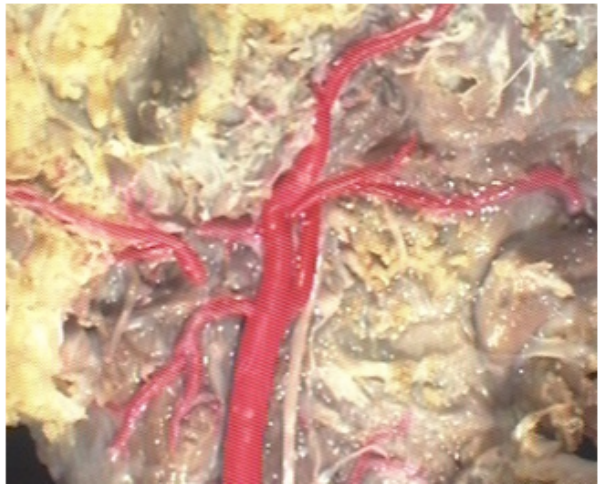

Fig. 5 Left thyro-linguo trunk originating from the medial aspect of the common carotid artery, $13 \mathrm{~mm}$ below its terminal bifurcation

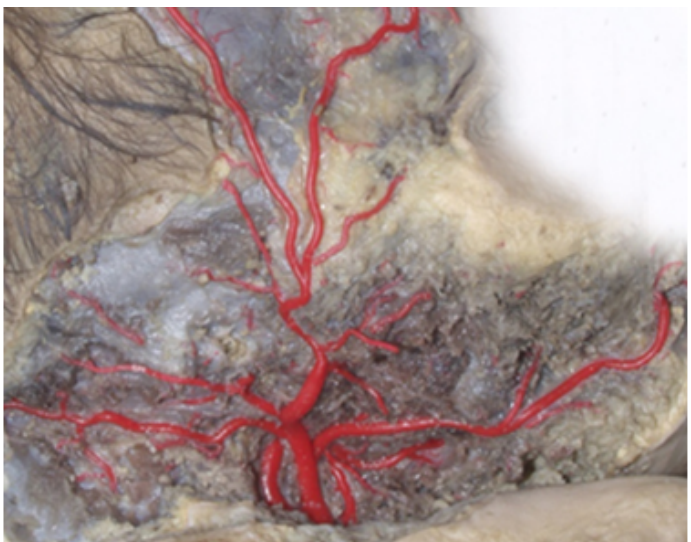

Fig. 6 Right thyro-linguo-facial arterial trunk, with the origin on the posterior medial face of the external carotid artery, $14 \mathrm{~mm}$ above the common carotid artery terminal bifurcation aspect of the external carotid artery at $2.5 \mathrm{~mm}$ above its origin, and in the other case the origin of the arterial trunk, with a length of $8 \mathrm{~mm}$, was on the postero-medial face of the common carotid artery at a distance of $3 \mathrm{~mm}$ below its terminal bifurcation.

In one case $(0.69 \%$ of 144 cases), we met a thyro-linguofacial trunk (fig. 6), with a length of $5 \mathrm{~mm}$, originating from the postero-medial face of the right external carotid artery, $16 \mathrm{~mm}$ above the common carotid artery bifurcation.

Among the 144 evaluated cases, independent superior thyroid arteries were found in 141 cases $(97.92 \%$ of all cases), 75 cases on the right ( $98.68 \%$ of the total right) and 66 cases on the left ( $97.06 \%$ of the total left). Concerning the origin of the thyroid arteries, the percentage differences between the right and left arteries are minimal, being between 0.48 to 1.46 percent. Thus, when the origin of the superior thyroid arteries was from the external carotid artery, the left ones were more frequent with $0.97 \%$, when the origin was from the common carotid artery, the right ones were more frequent with $1.46 \%$ and in the case of the origin level at the bifurcation of the common carotid artery, the left thyroid arteries were more frequent with $0.48 \%$. So, of the 141 cases, the superior thyroid arteries had their origins in the external carotid artery in $63.12 \%$ of cases, with $26.24 \%$ more than the origins from the common carotid artery and its terminal bifurcation. On the right, the difference was $25.34 \%$ while on the left the difference was $27.28 \%$.

We consider that the origin of the superior thyroid artery from the external carotid artery as a high origin whiles the origins from the common carotid artery or from its terminal bifurcation are low origins. When the superior thyroid artery originates from the common carotid artery or its terminal bifurcation, the first branch of the external carotid artery is the lingual artery.

Large percentage differences appear in regard to the surface of the origin of the superior thyroid arteries, differences ranging from 1.70 to $11.58 \%$. The right superior thyroid arteries emerged from the medial aspect of the origin artery more often, with $11.58 \%$, compared to the left arteries, while the left arteries had their origin from the posterior medial face more frequent with $10.30 \%$ compared to the right ones. Regarding the origin from the posterior surface of the origin artery, there are differences of only $1.70 \%$ in favor of the left ones, while the origin from the anterior-medial surface was more frequently, with $1.94 \%$, on the right side. There was no left superior thyroid artery to originate on the anterior medial face of the external carotid artery.

The distance between the superior thyroid artery and the lingual artery was between 4 to $25 \mathrm{~mm}$, in directrelation to the origin of the superior thyroid artery. Thus, when the origin was from the external carotid artery, the distance was 5 to $25 \mathrm{~mm}, 10$ to $22 \mathrm{~mm}$ on the right and 5 to $25 \mathrm{~mm}$ on the left. When the origin was from the common carotid artery, the distance was 4 to $20 \mathrm{~mm}$, on the right side being 4 to $20 \mathrm{~mm}$ and 11 to $20 \mathrm{~mm}$ on the left. When the superior thyroid arteries had their origins at the bifurcation of the common carotid artery, the distance was 10 to $24 \mathrm{~mm}, 10$ to $18 \mathrm{~mm}$ on the right and 16 to $24 \mathrm{~mm}$ on the left.

On a number of 24 cases we were able to compare the origin of the superior thyroid artery on both sides, noting that in 21 cases (87.5\% of cases) the left arteries showed a higher origin while in only 3 cases ( $12.5 \%$ of cases) the right arteries originated higher than the left ones; there was no case with same level origins.

By measuring the external carotid artery diameter below and above the superior thyroid artery origin on a number of 18 cases, we found that, above the superior thyroid artery 
origin the external carotid diameter decreased with 0.1 to $1.2 \mathrm{~mm}$ (fig. 7).

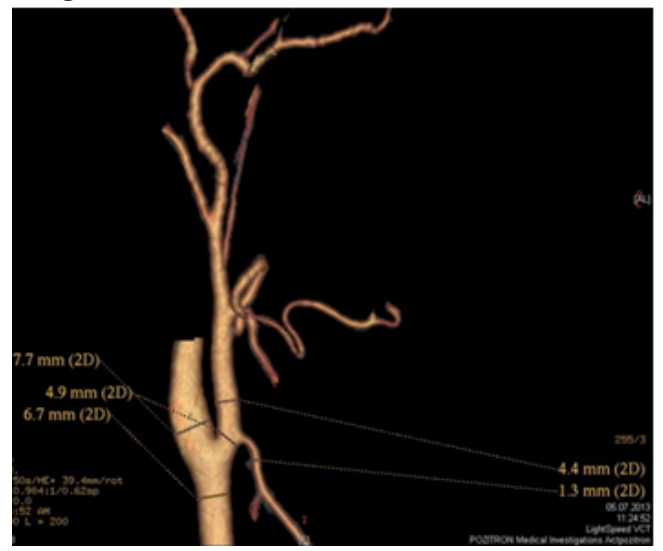

Fig. 7 The right superior thyroid artery has a caliber of $1.3 \mathrm{~mm}$; the external carotid has a $4.9 \mathrm{~mm}$ caliber below the superior thyroid artery origin and $4.4 \mathrm{~mm}$ above the superior thyroid artery origin

The superior thyroid artery origin from the external carotid artery was found more frequently with $11.80 \%$ compared to [10] and $8.675 \%$ compared with the results of [16], but lower with $10.2 \%$ than [15]. We also found significant differences for the common carotid origin, with $10.53 \%$ compared to [10]. Our results are lower in the case of the common carotid bifurcation origin, by $5.42 \%$ to [10], $4.17 \%$ to [16] and $5.17 \%$ to [15], also being smaller by $6.595 \%$ to [16] when the superior thyroid artery originates from the common carotid. According to [8], the most frequent origin of the superior thyroid artery is on the common carotid bifurcation while $[6,7]$ describes the superior thyroid origins above or at the common carotid bifurcation, also quoting the possibility of origin from the common carotid artery.

Regarding the origin from the external carotid artery, we found that the distance to the terminal bifurcation of the common carotid may be up to $22 \mathrm{~mm}$ on the left side and $14 \mathrm{~mm}$ on the right, [8] giving a distance of 3 to $5 \mathrm{~mm}$, $[6,7]$ finding the superior thyroid origin above or at the level of the common carotid bifurcation and [12] describes the origin of the superior thyroid artery at about 10 to $12 \mathrm{~mm}$ from the common carotid bifurcation.

According to $[5,9,12]$, the superior thyroid artery origin is on the anterior surface of the origin artery, while we frequently found that the origin is on the medial surface, an aspect also noticed by [16-18].

When the superior thyroid artery originated from the external carotid artery, the superior thyroid artery was its first collateral branch, an aspect also mentioned by [5-8], rarely being possible that the first collateral branch of the external carotid artery to be the ascending pharyngeal artery $[9,13]$, a variant that we have not met.

Considering the incidences of the superior thyroid origin from the common carotid artery, as reflected in the literature we consulted, we found, with one exception, that our results are higher than in all other authors cited, with $20.53 \%$ difference to [19], $15.12 \%$ to [20], $10.53 \%$ to [10], $8.21 \%$ to [21], $7.43 \%$ to Quain [cited by 20 ] and $3.53 \%$ to [22]. As we mentioned our results are lower by $6.595 \%$ compared to [16].

We found two cases of thyro-lingual trunk, one originating from the external carotid artery $(0.69 \%$ of all cases), a lower percentage with $3.31 \%$ than [11] and by $1.31 \%$ than [10]. The second thyro-lingual trunk originated in the common carotid artery, [10] finding it in a percentage less than $1 \%$ of cases. For $[6,7]$, the thyro-lingual trunk is not rare, and Vuillième and Bruneton, [cited by 22] and
[23] each describe one a case of thyro-lingual trunk originating from the common carotid artery, $30 \mathrm{~mm}$ below its terminal bifurcation.

Much more rare are the thyro-linguo-facial trunks [24] that we encountered as a single case, on the left $(0.69 \%$ of cases), originating from the external carotid, while [10] gives a percentage less than $1 \%$ of cases.

\section{Conclusions}

The superior thyroid arteries may originate as an independent artery or as arterial trunks; w e encounter the latest version only in $2.08 \%$ of cases, as thyro-lingual and thyro-linguo-facial trunks. As independent arteries, the superior thyroid arteries originate most often at different levels of the external carotid artery, this origin being more frequent with $40 \%$ than the origin from the common carotid artery and by $48 \%$ compared to the origin from the common carotid bifurcation [25]. The literature speaks of the common carotid artery terminal bifurcation [26], butwhen the origin of the superior thyroid artery is from the terminal common carotid, we propose to use the expression of terminal branching or the common carotid artery trifurcation.

When a significant decrease in caliber of the external carotid artery occur above the superior thyroid artery origin (over $0.5 \mathrm{~mm}$ ), this can be explained by the fact that the carotid sinus may be extended to the external carotid, the origin of the artery being located above it.

The statistical differences between our results and those found in existing literature may be attributed primarily to the total number of cases on which we worked and also working methods. Possible caliber differences may appear due to the fact that we have performed them on angioCT, most authors executing them on formalinized or injected corpses, procedures that may induce erroneous results, or by X-ray or ultrasound, giving differentresults compared to angioCT methods. Probably, these differences may be attributed to other causes, such as the geographic area where the study was conducted and the amount of time the results were obtained.

\section{References}

1.***Federative Committee on Anatomical Terminology, Terminologia Anatomica. International Anatomical Terminology, Thieme StuttgartNew York, 1998, p. 79-80

2.FALLER, A., SCHARER, O., Acta Anat., 4, 1947, p. 119-122

3.FONTAINE, C., DRIZENKO, A., Les arteres de la tete et du cou. In: Chevrel JP, Anatomie clinique, Tete et cou, Springer-Verlag, Paris, 1996, p. 404

4.ROUVIERE, H., DELMAS, A., Anatomie Humaine. Descriptive, topographique et fonctionnelle. Tome 1, Tete et cou, Ed. Masson, Paris, 1997, p. 200-201

5.STANDRING, S., Gray's Anatomy. The Anatomical Basis of Clinical Practice, Elsevier Churchill Livingstone, 2005, p. 544-545

6.TESTUT, L., Traité d'anatomie humaine. Angeiologie, livre IV, Gaston Doin, Paris,1921, p. 127-129

7.TESTUT, L., Traite d'Anatomie humaine. Angeiologie. Gaston Doin, Paris, 1924, p. 541-542

8.PATURET, G., Traite d'Anatomie Humaine, Ed. Masson, Paris, 1964, p. $271-276$

9.MOORE, L.K., DALLEY, F.A., Anatomie medicale. Aspects fondamentaux et applications cliniques, De Boeck Universite, Bruxelles, 2001, p. 1018

10.LIPPERT, H., PABST, R., Arterial Variations in Man. Classification and Frequency, J.F.Bergmann Verlag, Munchen, 1985, p. 83-85

11.SCHUNKE, M., SCHULTE, E., SCHUMACHER, U., VOLL, M., WESKER, K., Atlas d'Anatomie. Cou et organes internes. Maloine, Paris, 2007, p. $23,27,49$ 
12.BOUCHET, A., CUILLERET, J ., Anatomie topographique, descriptive et fonctionnelle, Vol.2, Le cou. Le thorax, Simep, Paris, 1991, p. 715,757 13.KAMINA, P., Precis d'anatomie clinique, Tome II, Ed. Maloine, Paris, 2002, p. 225

14.GLUNCIC, V., PETANJ EK, Z., MARUSIC, A., GLUNCIC, I., Surg. Radiol. Anat., 23, 2001, p.123-125

15.PANKAJ, G., ASHU, S.B., SANJ AY, T., ATIN, K., BIDHU, K.M., ALOK T., ATUL, S., Indian J. Radiol. Imaging, 24, no.1, 2014, p. 66-71

16.GAVRILIDOU, P., Morphological considerations on the external carotid artery (Consideratii morfologice asupra arterei carotide externe), PhD Thesis, Constanta, Romania, 2013

17.POPA, C.C., BADIU, D.C., ANDRONACHE, L.F., et al., Rev. Chim. (Bucharest), 70, no. 1,2019, p.331-335

18.TULIN, A.,ALECU, L., POIANA, C. etal., J ournal Of Mind And Medical Sciences,5,2018,no.2,p.278-283

19.AKYOL, M.U., KOC, C., OZCAN, M., OZDEM, C., Otolaryngol. Head Neck Surg., 116, 1997, p. 701-705
20.POISEL, S., GOLTH, D., Wien Med. Wochenschr., 124, 1974, p.229232

21.ADACHI, B., Das Arteriensystem der J apaner, Verlag der Kaiserlich Japanischen Universitat Kyoto, 1928, p. 43-96

22.ISSING, P.R., KEMPF H.G., LENARZ T., Laryngorhinootologie, 73, 1994, p.536-537

23.LEMAIRE, V., JACQUEMIN, G., MEDOT, M., FISSETTE, J., Surg. Radiol. Anat., 23, 2001, p.135-137.

24.VELNIC, A.A., HANGANU, B., PETRE-CIUDIN, V., IOAN, B.G. Forensic Science International, 277, 2017, Suppl. 1, p. 209-209.

25.DIACONU, C.C., BALACEANU, A., GHINESCU, M. Acta Medica Mediterranea, 31, 2015, p. 339-341.

26.BUHAS, C.L., MIHALACHE, G. JUDEA-PUSTA, C.T., BUHAS, B., JURCA, M.C., IOVAN, C. Rom J Leg Med, 26, 2018, p. 249-253.

Manuscript received: 8.12 .2018 